\title{
$\nVdash_{\mathfrak{m} m a r k z}$
}

on

\section{THE EFFECTS OF RESPIRATION ON THE CIRCULATION, AND}

\section{THE PULSUS INSPIRATIONE JNTERMITTENS} VEL PULSUS PARADOXUS.

By PATRICK WATSON WILLIAMS, M.D.Lond.,

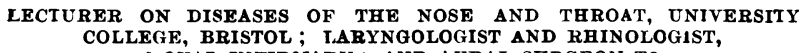

VICE-PRESIDENT OF THE LARYNGOLOGICAL SOCIETY OF LONDON.

To the laryngologist the import of the pulsus paradoxus concerns mainly its occurrence in acute dyspnoea from laryngeal obstruction, but in general medicine the occurrence of the phenomenon has been noted in various conditions. It is a questlon whether these respiratory undulations are due to respiratory pump action acting on the heart and intrathoracic vessels, or to nervous impulses influencing the heart and vessels; in other words, Are they myogenetic or neurogenetic, or both ?

My attention was aroused some years ago when, as Physician in charge of Clifton College, I had to examine every new boarder on entering the school, and I was astonished to find that respiratory undulations were so obvious as to be readily perceived by the finger on the radial artery in a large proportion of the most healthy specimens of English boys, particularly on their taking a deep inspiration. I soon learned that, so far from indicating an abnormal condition, well-marked respiratory undulations in the pulse implied, if anpthing, that the boy would make a good sportsman. At this school paperchase runs are the chief form of exerciee during the Easter term, and towards the end of the term they have what are known as the Long and Short Penpole Cup run-the former being a cross-country run of about nine miles and the latter seven miles. I may add incidentally that only those who are, after medical examination, pronounced fit for such runs are allowed to take part in them; and before starting in the cup runs each boy has to be examined medically and certified as fit. The J.ong Penpole, confined as it is to the elder boys, is especially a severe test of running power and physical fitness above the normal ; but during the eight years $I$ held the office as physician to the echool not only was no boy whom I had passed even the worse for his competition, but no boy was even temporarily upset, or required being seen by me after the Long Penpole run. But in a large number of those pronounced fit for this cup run I found respiratory undulations (with deep inspirations)well marked. A good example is furnished by a boy aged about 17 , who was first favourite for the cup run of the year, and who outran all competitors and came in very fit. His resplratory undulations were so well marked that prior to the run the pulse wave was obviously diminished during quiet respiration, and no pulse was felt following deep inspirations. The pulse tracing appended, which was taken forty. eight hours after the run, appeared to the finger indistinguishable in character from the pulse before the race.

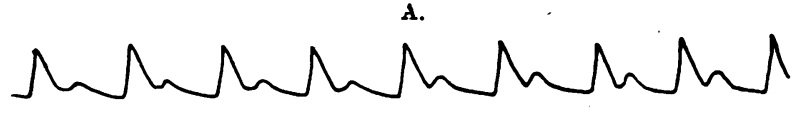

B.

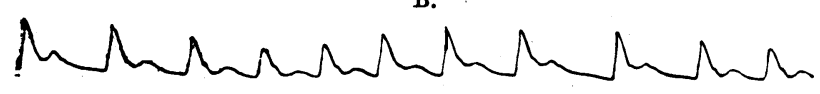

C.

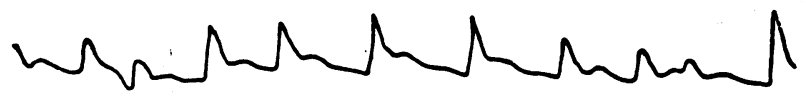

Fig. 1. - Three pulse tracings taken on the same day trom a healthy lad. A, Quiet respiration, B, with full inspirations, and $c$, with deep inspirations. In $B$ and $c$ inspiration coincides with the smaller prolonged diastole.
Such observations convinced me that the so-called "pulsus paradoxus" met with in laryngeal obstruction was merely a physiological phenomenon, or at any rate was a pathological exaggeration of a physiological condition. I regret that this pulse traclng, like those of Sir James Barr, ${ }^{1}$ in his recent contribution on the effects of respiration on the circulation, loses value from the fact that no simultaneous record of the respiration curve was made. But it may be noted that, following the commencement of inspiration, the pulse frequency and the tension increased, while during expiration the converse obtalned, the slowing of the pulse being dae to prolongation of the diastole-that is, it is the youthful type of irregularity of Mackenzie. This author states" that he "had come to the conclusion that all children at gome time or otber present this form of irregularity," and that he has "often found it take on a respiratory rhythm, and no doubt some cases are due to respiration."

Oliphant Nicholson, who, like J. Mackenzie, extensively used the graphic metbod of recording pulse and respiration tracings, states that extensive employment of the sphygmograph in children leads him to the conclusion that this pulse variation is almost invariably met with in all conditions of laboured breathing, whether fast or slow.

Sir James Barr ${ }^{3}$ has recently recapitulated some of the many views advanced from time to time, to account for the production of the palsus paradoxus, or the effects of respiration on the pulse. Variations in the intrathoracic pressure resulting from inspirations and expirations influence the circulation, and Sir James Barr has adduced experimental and clinical evidence which at first sight seems to prove that such respiratory variations in intrathoracic pressure satisfactorily account for the pulsus paradoxus or pulsus inspiratione intermittens. That respiratory pump action is a potent factor in the production of the respiratory undulations in arterial tension and pulse rhythm is certain, but we may recall certain physiological factors that cannot be ignored, and which show that the subject is much too complicated to be covered by such a simple physical explanation alone.

That respiratory movements produce regular variations in the arterial pressure, which are known as respiratory pressure variations, or respiratory undulations, bas been long recognized by physiologists; and that these variations or undulations are in part due to the fact that the heart and intrathoracic blood vessels are subject, like the lungs, to the pumping action of the respiratory movements, is beyond the region of controversy. The experimental and physiological proofs of these universally accepted facts are found in most modern textbooks of physiology.

During an inspiration the pressure around the heart and all intrathoracic vessels is considerably less than that of the atmosphere outside the chest. The negative pressure affects the thin-walled elastic veins, containing blood at relatively low pressure, more than the thickwalled arteries with their contained blood at relatively high pressure, hence the veins are dilated by the increased amount of blood driven into the chest from the systemic velns. But the same negative pressure aids the flow of blood to the right heart leading to a stronger ventricular contraction, or at least to a larger amount being tjected, and consequently more blood reaches the left ventricle, and more blood escapes by the aorta, so arterial tension rises. With obstructed inspirations a still greater but similar effect is produced, for the negative pressure which increases the capacity of the lung reservoir can only do so by dilating the vessels, thereby correspondingly facilitating the onward flow of the blood to the right heart, and from the right ventricle (though the negative pressure, even apart from any pericardial adhesions, etc., will have some tendency to interfere with contractions, and to aid the diastole of the cardiac cavitles).

Thus an inspiration first widens the pulmonary vessels and increases the lung reservoir capacity; but, secondly, by lessening resistance, it increases the rate of flow through the pulmonary vessels. As Professor Michael Foster ${ }^{4}$ points out, the first factor is a transient and passing one; the second factor is more lasting - and this applies not only to inspiration, but conversely to the effects of expiration. "These two factors produce opposite effects, and hence the total result of any particular kind of respiration will depend on their relative prominence. 
With quickly repeated respiratory movements the first factor comes to the front; when the respiratory movements are more slowly repeated and more slowly carried out, the second fastor is the more potent."

Hence we must inquire whether there is not another factor in producing the observed effects of respiration on the circulation, one which Sir James Barr disallows, he being apparently a pure myogenist.

First, it has been proved experimentally that the respiratory, cardio-inhibitory, and vaso-constrictor centres in the medulla oblongate act to a certain extent in unison, or, as Sir Michael Foster ${ }^{6}$ puts it, "while the respiratory centre in the spinal bulb is at work, sending out rhy thmic impulses of inspiration and expiration, the neigbbouring cardio-inhibitory centre is, as it were by sympathy, thrown into an activity of such a kind that its infuence over the heart waxes with each expiration, and wanes with each inspiration."

The prool of this is afforded by the $\epsilon$ ffects of artificial res piration on an animal under curare, when, despite the fact that the mechanical conditions affecting the intrathoracic viscera as regards atmosphere pressure during respiration are reversed, the respiratory undulations remain the same, in time and character, as during natural respiration; and perhaps still more conclusively by the rhythmical undulations, the so called Traube Hering curves which appear when, in an animal under curare, artificial respiration is suspended-rhythmical undulations which are similar to and seem to take the place of the respiration undulations under artificial or ordinary respiration. Still farther evidence of the influence of the medullary centres on the pressure curve is affurded by the strlking fact that, for example in the dog, the pulse rate is quickened during the rise of the respiration undula. tions and slowed during the fall (Foster, Landois and Stirling, etc.) The rise in pressure that occurs on cessation of artificial respiration is due to an increase in peripheral resistance resulting from widespread vaso constriction. Tae same inflaence is seen in the pulse tracings of man.

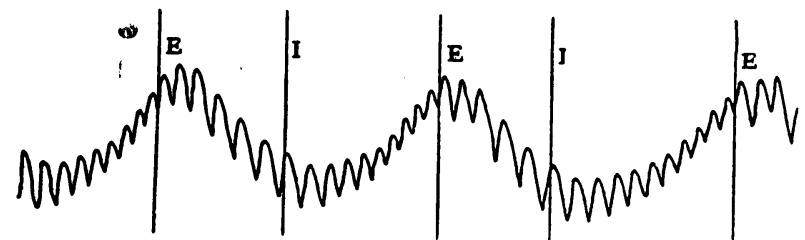

Fig. 2.-Carotid Blood-Pressure Tracisg of a Dog (STirling).

$I=$ commencement of inspiration. $E=$ commencement of expiration. The respiratory u udulations are due, in part at any rate, to a stimulation of the vasomotor centre, which runs parallel with the respiratory movewents, and which causes the arteries to contract, with consequent raising of the arteria pressure. The smaller rumber of pulse beats during the greate part of expiration is due to the activity of the curdio inhibitory during inspiration

N.B - Dog under anaesthesia, but without artificial respiration, and vagi not divided.

If we take no account of the medullary centres, and seek to explain this variation in pulse-rate and rise of pressure by respiratory pump action alone, we are confronted with the fact that section of both vagus netves does a way with this difference in the pulse, in inspiration and expiration, showing clearly that the cardio-inhibitory centre is one essential cause of the diff-rence. At the same time it should be borne in mind that this is not, as Sir James Barr surmises, a reflex -he says, "the time element is against any such theory as a cause of the pulsus para. doxus"-but a stimulus from different bulbar centres, coincident with the inspiratory and expiratory impalses. It is noteworthy, too, that in the tracing from Landois and Stirling the influence does not correspond exactly with the commencement of inspiration and expiration, but is seen to be one or two heart beats later in modifying the pulse.

To return to the views advanced by Sir James Barr, which he illustrates by pulse tracings taken on a healthy young man of 22 the effect on the pulse produced by Mü!ler's experiment. Daring the forced inspiratory movement on expanding the chest the lung reservoir is increased, and he states that "if there be a large lung reservoir to fill, the pulse may disappear in many of the superficial arteries for several beats. When the lang reservoir overflows the heart fills up the empty arteries, and the pulse again returns even while the chest is fully expanded. . . . Unlike the Valsalva experiment, the heart at no time stops, and its active movements can be watched under the $x$ rays" In the first experiment, " after the first two normal pulse waves, the chest was fully expanded but no air admitted, and the pulse completely disappeared at the wrist for about thirty beats, and then when he relaxed the respiratory effort and opened his glottis the pulse immediately reappeared." The next "two tracings were taken in euccession. In the first there are three normal pulse waves, and then the chest was expanded, with obliteration of the pulse; after a short period the second paper was inserted, and it shows a return of the palse while the chest was still fally expanded. . . These tracings show that the artery which was at first depleted gradually filled up and exhibits a marked rise in blood pressure.* This is exactly what has been noticed in some cases of mediastinitis with the so-called pulsus parodoxus."

A difficulty in accepting Sir James Barr's views as an all-sufficient explanation at once presents itself-namely, that as the heart's active movements continue the whole time, and the pulse wave completely disappears at the wrist for about 30 beats, not only is it remarksble that the young man did not faint but was able to maintain (presumably in the erect posture) the great effort involved if his carotid and vertebral arteries, like the radial, remained empty for 30 heart beats; further, the lung reservoir would have to be extraordinarily large. With every gystole of the normal heart about $172 \mathrm{c.cm}$. (180 grams) of blood are discharged into the aorta, and the same amount under normal conditions is discharged at each contraction of the right ventricle, and "the mean time required for the circulstion is ascomplished during 27 heart beats-for example, for man 322 seconds, supposing the heart to beat 72 times per minute." $B$ But in Sir James Barr's case, the heart while continuing to beat failed to give a pulse for about 30 beats, notwithstanding the fact that the blood flow, at least towards the right heart, was actually facilitated by the conditions of the exp:riment. Why? Sir James says because the ventricle and the arteries were empty. But failure of the circulation could not be due to the right ventricle being overdistended, for, even while conditions favouring distension were continuing (and presumably aggravated by de oxygenáted blood), the pulse reappeared, and reappeared with increased tension.

Yet Sir James Barr contends that during all the period of 30 heart beats the lung reservoir was being filled, and that, too, at the expense of all the systemic arteries and veins! As the relative quantities of blood normally distributed in the pulmonary and systemic circulations is about 1 to 4 , the lung reservolr would require enormous reserve capacity to dispose of all this blood without showing any signs of "overflow" for 30 heart beats, and without any marked and continuous fall in blood pressure heing indicated on the sphygmographic tracing. It is true his pulse tracing shows (if a sphygmographic base line by falling shows anything) an initial slight fall of pressure, but after a period. corresponding to 5 pulse beats, the tracing No. 1 shows a temporary rise in pressure. becoming slightly higher than it was before the inspiration was taken. His No 2 pulse tracing likewise shows, as he point s out, that the pulse when it appears, "exhibits a marked rise.in blood pressure"-that is, while the chest was still fully expanded and the inspiration effort continued. This tracing, however, shows other features of interest-namely, that the high-tension pulse during and towards the end of the inspiration period is more frequent than it was eithe $r$ before the inspiration (that is, with a low-tension pulse) or after the glottis was openf $d$ and after respiration was resumed. Now, rise in blood pressure may be due either to increased amount of blood in the artery or to increased peripheral resistance, vascular constriction. But Sir James Barr has explained that the artery is empty, and though it is conceivable that after several rapid contrastions of a well-filled ventricle the artery would be overfilled and blood pressure high, this could not occur if at first the ventricle was emptying itself into nearly empty arteries of low tension; the pulse trazing would be dicrotic at first though it might show increased tension later. There is another explanation, however-namely, that 
during an inspiratory effort the vaso-consticictor centre in the medulla is active, raising peripheral resistance by increasing arterial tone, while during respiration it is less active, and so we get a more dicrotous pulse.

A further point is the increased frequency of the ventricular systole during the inspiratory phase and during the period of increased blood pressure, as compared with the frequency during the individual's normal blood-pressure period of ordinary respiration. I note that Sir James, referring to the Muller experiment, states that with the inspiratory expansion of the chest " the capacity of the lung reservoir is increased, so the immediate effect is a diminished supply to the $\mathrm{f} f \mathrm{ft}$ side of the beart, and the systemic pulse becomes slower." His pulse tracings afford no evidence of this, but in tracings given by Stirling, Foster, Nicholson, and invariably in my cast $\mathrm{s}$ showing respira. tory undulations, the pulse becomes more frequent after the inspiratory impulse - that is, during the early phase of inspiration. Mackenzie" states that "when the pulse beat is evidently diminished in size through respiratory interference, its duration is likewise shortened. I think the explanation is that the cardio-inhibitory centre is inhibited during inspiration (that is, by inspiration impulses) and more active during expiration.

\section{MMMMMWMWM}

Fig. 3.-A type of irregularity due to respiration in an infant, (normal breathing). (Oliphant Nicholson.)

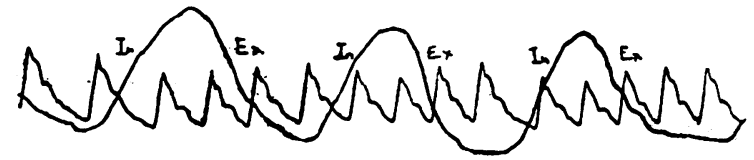

Fig. 4.-Respiratory irregularity where more than a single pulse wave is affected (really a pulsus paradoxus). (Oliphan

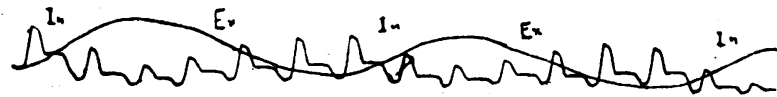

Vig. 5. - In spiratory diminution of the pulse curves in a slight trne pulsus paradoxus of mediastino-pertcarditis.) (Nicholson.)

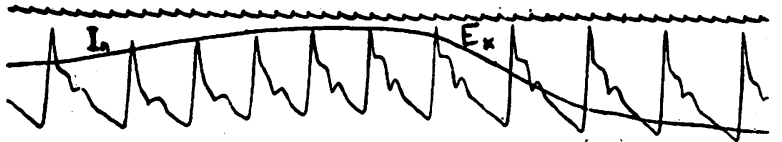

Fig 6.-Quickening of the pulse with deep inspiration (loss of Q regaining th influen.

Again, Sir James states that "it is impossible to produce a negative pressure within the thorax equal to the positive preseure within the sorta, and 80 there can be no aspirating effect interfering with the ordinary course of the circulation." He also assumes that the elastic tension of the lungs is $=10 \mathrm{~mm}$. Of mercury, but with the chest fully distended it is $=30 \mathrm{~mm}$. of mercury, and this, added to the $80 \mathrm{~mm}$. of negative pressure in his Johannes Müller experiment, gives $760 \mathrm{~mm} .-(80+30)$, that is $650 \mathrm{~mm}$., as the atmospheric pressure on the extrapulmonary contents of the thorax-for example, the heart and large vessels-as compared with $760 \mathrm{~mm}$, the atmospheric pressure on the vessels outside the chest. That is to say, $110 \mathrm{~mm}$. of negative pressure is opp:sing the contraction of the auricles and ventricles, and equally assisting their diastole, "while the chest is fully expanded.".

Taking the blcod pressure in the aorta as 200 to $250 \mathrm{~mm}$. of mercury, a sudden negative pressure of $110 \mathrm{~mm}$. is quite enough to take into serious consideration. But Sir James assumes that the blood in the large arteries is rapidly * emptied into the capillaries and veins, and that, consequently, the arterial pressure falls

* Fo rapidly that in his two pulse tracings, at any rate, the ventricle had not time to produce a single pulse wave after the chest was be slowed. and the pulse is obliterated at once. There must be some blood in the intrathoracic aorta, but as the extrathoracic arteries are-shall we say?-nearly empty, the arterial tension must be very low, and so, too, the aortic blood pressure. Then the intrathoracic aorta must be underfilled, especially if the $110 \mathrm{~mm}$. head of pressure outside the chest (which is such \& potent factor in driving blood into the chest from the veins) does not operate in 8 similar monner on the flaccid arteries. But if the aorta is flaccid-that is, not quite distended-then the negative preesure of $110 \mathrm{~mm}$. of mercury certainly has full play, and it will tend to suck blood back into the chest. And I can further imagine that the diminished tension in the intrathoracic aorta will damp down any pulse wave started by the con'racting ventricle; and this lessened pulse wave will be still further and sapidly damped down when it reaches the extravascular arteries, subjected as they are to higher atmospherlc pressure, even if the $y$ be not in a state of active vascular constriction.

Before leaving Sir James Barr's thesis, I would refer to one other point that he touches on. He refers to Dr. Brockbank as having observed the pulsus paradoxus in a case of acute laryngitis, and later on reminds us that in cases of laryngeal diphtheria in elder children with firm chest walls we have a modified Müller's experiment. But, says he, "In very young children where there is almost complete obstruction of the larynx we do not get the pulsus paradoxus, because when the child attempts to expand its chest the atmospheric pressure drives in the solt, pliant cartilages behind which the heaxt and great blood vessels are situated, and thus the respiratory pump is thrown out of gear." Yet in reply I may quote from Brockbank's own article as follows: ${ }^{8}$ '. The extent to which the pulse disappears during inspiration varies directly with the severity of his affection (acute laryngitis); and as the recession of the lower half of his chest also varies according to the amount of obstruction to the entrance of the air into the chest, the former symptom may be taken as an indication of the presence of the latter. ... The 9 cases to which I have referred above were children nnder 2 years of age. ... In some cases-in children with a flexible sternum in whom the recession of the chest was extreme-one cannot help wondering whether direct pressure on the heart from the retracted sternum does not enter into the causation of the leeble beats."

I may further point out that in acute laryngeal obstruction there is as much (if not greater) obstruction to the exit as to the entrance of air; the expiratory dyspnoea is not so great for the reason that the expiratory force is always greater than the inspiratory. But Sir James, while demonstrating the effect on the pulse of forced obstructed inspiration (Müller's experiment), has also demonstrated the effect of forced obstructed expiration (Valsalva's experiment), and one may aek if the pulse is diminished or obliterated on inspiration, bf cause " in laryngeal diphtheria in elder children with firm chest walls we have a modified Muller's experiment," why does the pulse not disappear because in expiration we have a modified Valsalva experiment? It may be said, of course, that for the obliteration of the pulse by Val\&alva's experiment greater force is necessary, greater than is ever encountered in a diphtherilic child, but so, tóo, Mü'ler's experiment is never carried out with the force or with the duration of the experiment; while the rapid alternation of the Valsalva and Muller experlment that the child with laryngeal diphtheria exhibits, completely alters the force of the argument of Sir James, inasmuch as the one counteracts the other.

Perhaps we make a mistake in attempting to explain the pulsus paradoxus in all and every case as being due to precisely similar canses. I have never met with a case of pulsus paradoxus in mediastinitis. The late Dr. Thomas Earris, cited by Dr. Nicholsor" in his contributions on Indurative Mediastino-Pericarditis, quotes from Schreiber,

$$
\text { Fig. 7.-Disappearance of the radial pulse in taking a deep }
$$

who regarced as features characteristic of the true pulc us paradoxus that it "does not require for its development the inspiration to be deep." A typical pulee traoing in 
Púlge and Regpranion Tracings of Healthy Men during Quiet and Deep Regpiration. (1)

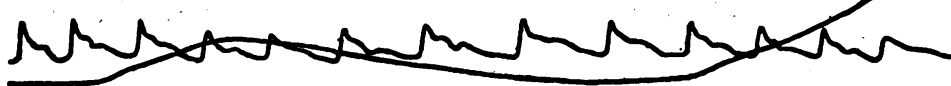

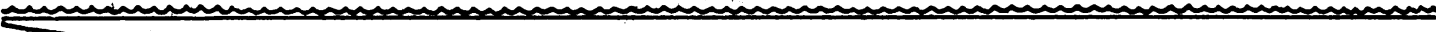

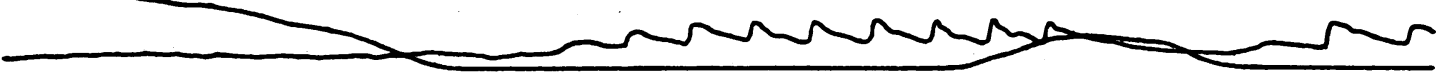

Fig. 9.-P., November 9th, 1906. Continuous portions of sphygmogram.

(1)

Whathonathon

(1)

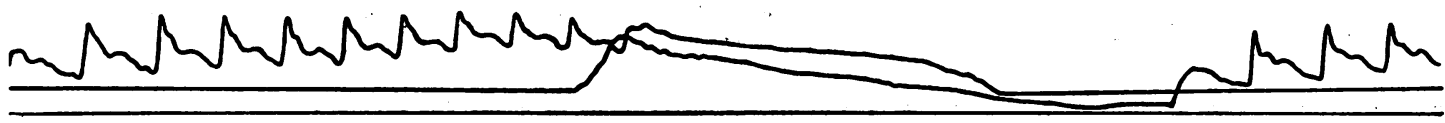

Fig. 10.-P., December 4th, 1905. Sitting. Continuous portions of a tracing.

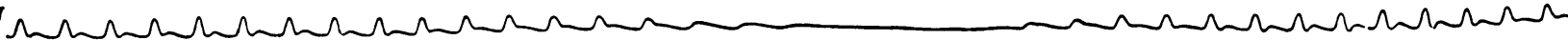
Fig. 11.-D., June 8th, 1907.

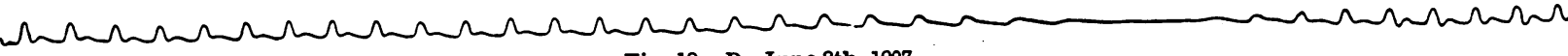
Fig. 12.-D., June 8th, 1907.

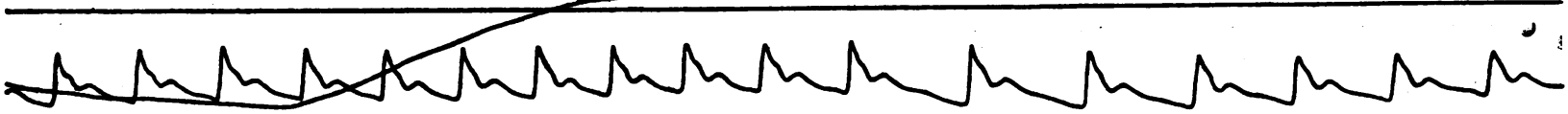
Fig. 13.-M., July 17th, 1906.

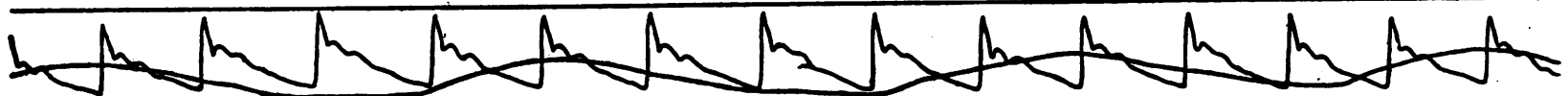

Fig. 14.-M., 2 p.m., July 17th, 1906.

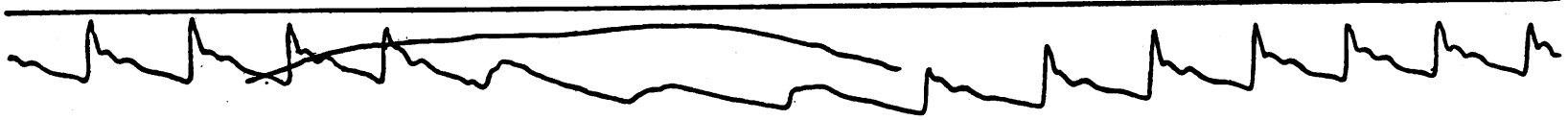

Fig. 15.-M., 2 p.m., July 17th, 1906.

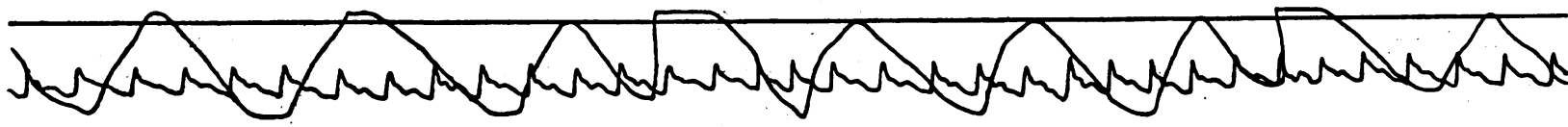

Fig. 16.-W., June 12th, 1905, 2 p m. Ordinary breathing.

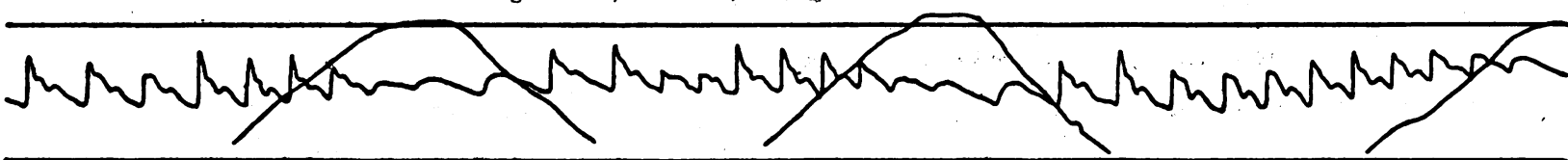
Fig. 17. -W., June 12th, 1906. Deep breathing.

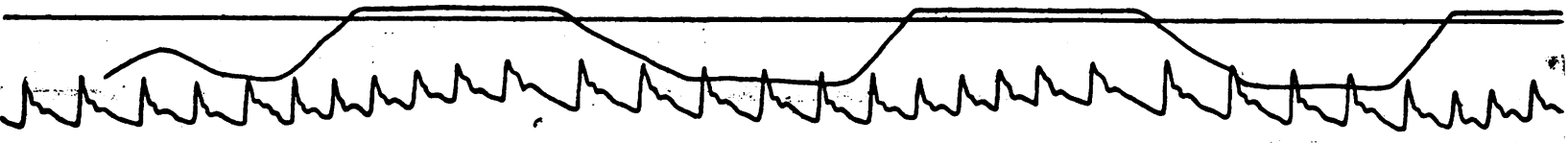


point is the following (Fig. 8), which with others Dr. James Mackenzie kinđly allows me to reproduce. It was taken from an apparently healthy youth, inspiratión belng'deep, but unobstructed.

$$
\begin{aligned}
& \text { A. }
\end{aligned}
$$

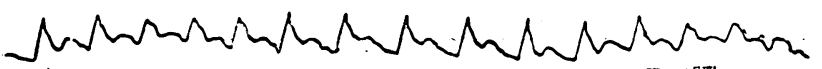

B.

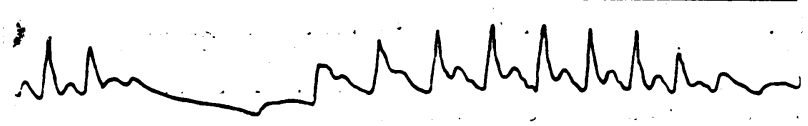

c.

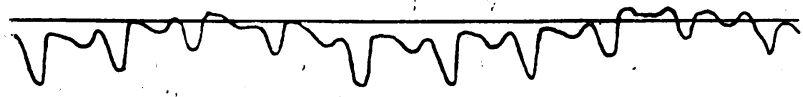

Fig. 8. -Three tracings from a neurasthenic young man. A, During quiet respiration, 13 and $c$, with deep inspirations, in each case corresponding with diminished ampltate in this and in the previous figure, the precise moment of inspiration and expiration, which were indicated on the sphygmograms, have not beel reproduced in the otherwise accurate reproduction.

Another tracing from a patient of $m y$ own in 1900, who was rather neurotic, and had an abnormally frequent pulse, but who had nothing else the matter with him, and who has slnce become a healthy architect, shows the $\in$ ffect of simple deep unobstructed inspiration on the pulse. The inspirations were through the open mouth, and the negative pressure could not have been more than a few millimetres of mercury over and above that resulting from the elastic tension of the lunga; nevertheless the obliteration of the pulse in this patient, as in Mackenzie's, was in this tracing complete.

In other tracings taken at the same time, and apparently with equally deep inspirations, the respiratory undulations were marked, but no obliteration of the pulse was shown by the tracing. I am strongly inclined to suspect that the obliteration of the pulse in this and in Sir James's and in Dr. Mackenzie's tracings are due to the instrument failing to receive pulsations from the smaller (constricted) radial artery. "It must always be borne in mind that a sphygmographic tracing is not the tracing of the pulsation of the artery, but of the tissues and liquids surrounding it." 10

The effect of respiration on the pulse has been the subject of investigation by Lieutenant-Colonel Deane, R.A.M.C., and he has kindly allowed me to see a large number of his excellent pulse tracing a from healthy men some of which I am enabled to reproduce (Figs. 9 to 18). This observer has very frequently obtained the pulsus paradoxus in healthy men with only long easy breaths but with no effort or straining whatever. These tracings are to be read from right to left, the respiration phase being indicated by the respiratory curve in each case. In "some the pulse obliteration appeared when straining after inspiration, in another the pulsus paradoxus continued through an inspiration and expiration, and then appeared at each ordinary quiet inspiration for a few times when the pulse resumed its ordinary characters. Again in others, when the breath is held after inspiring, the pulse is more frequent at first then slows with prolongation of disstole, and then sometimes quickens. It looks as though the bulbar rhythmical impulses which alternate habitually with inspiration and expiration continue to influence pulse frequency even with the breath held and respiration suspended, exactly as it does in a curarized animal when artificial respiration is suspended (see Figs. 13 and 18). Moreover, it is curlous that 'almost, though not quife, invariably the pulserate is quickened at the commencement of deep inspiration, that is, with the bulbar inspiratory impulse, even though it slows again with the chest expanded in respiration - that is, when the inspiratory bulbar impulse has passed off. There seems to be no exact relationship in Colonel Deane's tracings, and in my own, between the degree and force of inspiration and the amount of diminution in his pulse wave, and whereas at one time a fairly deep inspiration cauefs a slight respiratory undulation in the pulse tracing, another time, in the same individual, the tracing is a typical pulsus paradcxus.

In spasmodic asthma the dyspnoes is mainly expiratory, and the pulse tracing of slight spasmodic asthma recorded by Nicholson,? taken during the attack, is noteworthy (see Fig. 5).

The same author finds that the pulse and respiration tracings from children and adults show that the line of the tracing does not fall during deep inspiration, except in a.very small proportion of cases, and when it :does : so fall he considers it might be due to olight movements of his arm which affected the tracings during inspiration. "These observations seem to show that inspiration very often simply leads to a diminution of the pulse curve without lowering the level of the tracing. On the contrary it sometimes happens that there is a raising of the level of the pulse curves during this."

It would seem as though the vagus influence in inhibit. ing the heart on inspiration having been lessentd, with consequent acceleration of the pulse, "the reaction back to the normal rate was apt to be too extreme . . . and it does not immediately strike the proper balance with the accelerators," as Nicholscn ${ }^{9}$ puts it. This authority further reminds us that "it is not alwas $s$ the inspiratory act which ltads to a temporary diminution of the vagus influence, and, the refore, a faster pulse."

During ordinary respiration the neurc-vascular syst $\in \mathrm{m}$ is in perfect co-ordination, working under conditions to which they become completely "accustomed," but with deep respirations and in various abnormal conditions the co-ordination is less complete. The extraordinary inspiratory impulse unduly inhibits the cardio-inhibitory centre, and this, followed by a reassertion cf vagus control, often overehoots the mark. The trained runner or athlete quickly gets his "second wind"-that is, his splnal centres socn respond to the extra call on their uctivities. So, too, the medullary centres, always acting, us they must do, to ensure an equal pulge-wave despite the $\epsilon$ ver-varying intrathoracic pressure, declare their activity by respiratory undulations in the pulse wave when the respiratory medullary impulses are excessive.

Thus the effect of respiration on the circulation is exceeding]y complex, resulting from mechanical factors introduced by the pump action of inspiration and expiration, and from impulses generated in the bulbar cardioinhibitory and vasomotor centres coincident with the respiration impulses; and the effects vary accolding to the quickness or slowness of respiration, whether:it be natural or deep and forced, obstructed or free; while the strength of the heart beat, arterial tension,. the activity of the bulbar centres, and, we may add, the action of the abdominal muscles, the splanchnic area, and even the degree of oxygenation of the blood-all have varying influences in ; determining the final results. ... As the relative dominance of these different factors is - so variable, the results as shown in pulse tracings are also inconstant.

In children, as compared with adults, the spinal centres are unstable and reflexes overactive. Hence in yourg individuale, although their chest : walls are more pliable and less fitted to overcome atmospheric pressure on deep inspirations, the bulbar centres are very prone to obviously affect the frequency and force of the pulse; and when the larynx or main bronchi are obstructed the forcible inspiratory impulses very often result in the socalled pulsus paradoxus. That these effects on the pulse are wholly due to cardio-inhibitory or - vaso-constrictor centres is hardly po isible, but they are important, and I think the dominant factors.

\section{REFERENCES}

1 BRITISH Medrcal Journal, April 20th, 1907, p. 913. 2 The Study of the Pulse, p. 87. 8 Loc. cit A. Textbook af Physiology. p.- 652 . Textbook of Physiology. vol. il. p. 653. sixth edition. i A Textbonk ' Study of the Pulse, 164.8 BRI pludy $1314-1315$ 9 Encyclo, aedia Medica, vol. x, p.' 234.' 10 Textbook of pp. 1314-1315 9. Encyclo "aedia Medica,
Pathology, D. J. Hamilton, vol. j, p. 696.

THE late Mr.-Henry Howard Paul, fan actor and author, besides bequeathing $£ 400$ to the Hospital for Sick Children, Great Ormond Street, and $£ 300$ to the Royal Orthopaedic Hospital, directed that the residue of his estate, amounting, apparently, to some $£ 50,000$, should be divided between seven charitable institutions and funds, including Middlesex Hosnital. Universily (College Hospital, and Charing Cross Hosui al. 